\title{
EU-OUTRO: REFLEXÕES SOBRE A DIMENSÃO RELACIONAL NA PSICOTERAPIA EXISTENCIAL
}

DOI: $10.22289 / 2446-922$ X.V2EEA7

\author{
Lorena de Melo Alves Mozzer ${ }^{7}$ \\ Guilherme Bessa Ferreira Pereira
}

\section{RESUMO}

Este artigo realizado na forma de revisão da literatura teve como objetivo analisar a dimensão relacional, partindo dos conceitos elementares da filosofia de Martin Buber, para quem a relação é o evento primordial do ser humano. O estudo mostrou que Buber atribui que a abertura ao outro e ao diálogo conferem sentido a existência, através da relação. Ficou evidente sua influência nas reflexões sobre o encontro que se dá num contexto de terapia, mais especificamente através da abordagem psicoterapêutica existencial por meio do diálogo. Conclui-seque é muito importante pensar nas dimensões relacionais do trabalho terapêutico.

Palavras-chave: Relação; Alteridade; Encontro; Dialógica; Existencialismo.

\section{ABSTRACT}

This article will analyze the relational dimension, starting from the Philosophy's elementary concepts of Martin Buber, for whom the relationship is the primordial event of human being. Later, will investigate how the meeting takes place in a therapy context and through existential psychotherapy. Finally, will elucidate how the openness to the other and to the dialogue give meaning to the existence through the relation, as well as the Buberian influence in psychotherapy process in existentialistic approach.

Keywords: Relationship; Otherness; Meeting; Dialogical; Existentialism.

\section{INTRODUÇÃO}

Este trabalho iniciou-se com o intuito de sanar algumas questões próprias da existência de uma estudante de graduação em psicologia, sendo esta a autora desse estudo. Tais questionamentos iniciaram-se no sexto período do curso, tornando-se mais fortes e evidentes com o início dos estágios acadêmicos, mais precisamente os estágios no segmento da clínica de psicologia.

Várias indagações surgiram ao observar as relações intrapessoais e interpessoais, como elas se davam e qual seria a influência do Outro na individualidade

\footnotetext{
${ }^{7}$ Endereço eletrônico de contato: lorenamozzer@gmail.com
} 
do sujeito. Afinal, quem era esse outro com o qual o Eu estava em contato e o quanto tal encontro afeta a singularidade do sujeito.

Com o início dos atendimentos na clínica de psicologia, percebeu-se o quanto o mal-estar vivido pelo consulente advinha na maioria das vezes de suas relações mal estabelecidas e mais uma vez a maneira que o Outro interfere na vida do Eu, bem como a relação que se estabelece entre Terapeuta e Consulente que reverbera na existência de ambos dentro e fora do contexto terapêutico.

Pretende-se, portanto buscar uma melhor compreensão do Eu em relação com o Outro, no cotidiano e algumas implicações das relações na atualidade, e ainda da relação que se estabelece no encontro psicoterápico dentro do setting terapêutico, onde Eu (terapeuta) se relaciona com o Outro (consulente), utilizando para tal o legado de Martin Buber e sua influência na prática psicoterápica existencial.

O presente trabalho está pautado numa visão existencialista do modo de ser e existir, utilizando para tal o legado de alguns filósofos que refletiram sobre o assunto, utilizando principalmente as obras de Martin Buber e sua filosofia dialógica ou do encontro.

Para elucidar as questões levantadas anteriormente, este trabalho contempla inicialmente sobre o trabalho de Martin Buber. Destacando as reflexões do autor no que se refere à dimensão relacional da existência.

Posteriormente será discutido sobre o que é o Outro que participa desta reflexão relacional. Para tanto serão apresentadas as considerações de alguns autores sobre este tema.

Por fim, será discutido sobre a dimensão do trabalho terapêutico a partir da influência e considerações postas pela visão Buberiana, entendendo-a como fundamental na construção de uma estrutura de prática psicoterapêutica, especialmente aquelas que se auto definem como existenciais.

"Para se conhecer o homem não se pode partir da compreensão do aspecto individual, vendo-o apenas como definido em si mesmo. É necessário partir da instância relacional, do encontro entre o Eu e o Tu". (1)

\section{METODOLOGIA}

Outubro, 2016:2(Edição Especial):86-103. 
Este estudo foi realizado por meio de revisão não sistemática de literatura. Foram utilizados livros, artigos científicos, dissertações, monografias, teses, e manuais que foram conseguidos por meio de compra e empréstimo, bem como busca de base de dados da internet e busca em sites de instituições de ensino superior. No caso de buscas on-line as palavras chaves utilizadas para a pesquisa de materiais foram: encontro, existencialismo, relação, psicologia, filosofia, dialógica.

\section{MARTIN BUBER E A FILOSOFIA DO ENCONTRO}

Martin Buber, judeu de origem austríaca e de inspiração sionista, nasceu em Viena aos 8 de fevereiro de 1878. Era filósofo, escritor e pedagogo; atuou como um influente pensador do início do século $\mathrm{XX}$, apresentando e dando destaque para temas como o encontro e a relação em seus trabalhos, aspectos relacionais fundantes, segundo ele, da realidade de existência humana. Faleceu em Jerusalém em 13 de junho de 1965, aos 87 anos. $^{(2)}$

Aos 60 anos viveu um período considerado o mais produtivo de sua vida, quando publicou estudos dos mais diversos temas como: a Bíblia, o Judaísmo, e o Hassidismo, além de estudos políticos, sociológicos e filosóficos. Foi nomeado ao prêmio Nobel da Paz em 1959. Em suas publicações deu ênfase à compreensão de que não há existência sem diálogo, que o sujeito é um ser relacional.(2)

A filosofia de Buber é reconhecida como filosofia do encontro ou dialógica e foi fortemente influenciada por Feuerbach, Imannuel Kant, Frederick Nietzche e principalmente por Soren Kierkegaard. (3)

Buber considerava-se um homem atípico e, portanto, negava qualquer definição sistemática ou filosófica para suas propostas, ainda assim alguns autores o consideram um pensador existencialista. ${ }^{(4)}$

Buber elaborou em sua filosofia as palavras-princípio, que introduzem o ser humano na existência: EU-TU (relação) e EU-ISSO (relacionamento), duas atitudes básicas que o homem enfrenta diante do mundo. O Eu só existe em relação ao Tu ou ao Isso.(2)

As palavras-princípio são duas intencionalidades dinâmicas que instauram uma direção entre dois polos, entre duas consciências vividas e podem somente ser proferidas pelo Ser. ${ }^{(1)}$

A estrutura da vida é Dual, há dois mundos, há duas relações. Esta dualidade presente na vida se faz fundamental em sua filosofia. ${ }^{(1)}$

Outubro, 2016:2(Edição Especial):86-103. 
Eu-Tu é a relação ontológica base para a existência dialógica e só pode ser proferida na totalidade. A relação com o TU é imediata; não existe intermédio e nem obstáculos, ela é o esteio para a vida dialógica. Tem se então a abertura essencial do EU de um lado e, de Outro a imediata doação do ser. É extremamente importante, para Buber, ressaltar a irredutibilidade do Tu a um objeto que a atitude do sujeito determina e experimenta. Em hipótese alguma o Outro pode ser um objeto. O Tu não pode ser representado já que a apresentação é essencialmente presença. ${ }^{(6)}$

Neste encontro do Eu com o Tu, que é o meu Outro, acontece uma autêntica alteração, pois o Eu age sobre o Tu e o Tu, sobre o Eu. A pessoa que profere a palavra-princípio Eu está comunicando o fenômeno da essência do ser com o Outro, pois Buber parte do princípio que o homem só pode conhecer sua essência na relação com o outro. O eu, para quem o pronuncia é o Tu para quem o percebe. Essa é a condição da existência no mundo que aponta para o encontro. ${ }^{(2)}$

A palavra-princípio Eu-Tu só pode ser proferida pelo ser na sua totalidade. A união e a fusão em um ser total não pode ser realizada por mim e nem pode ser efetivada sem mim. O Eu se realiza na relação com o Tu; é tornando eu que digo Tu. Toda vida atual é encontro. ${ }^{(1)}$

Eu-Isso é o lugar da experimentação, do conhecimento e da utilização onde se instaura o vínculo objetivante. O mundo do Issoé experienciar algo que é mediado e indireto não havendo significante em si mesmo ou no entre. Não há entre.(1)

O Isso é a crisálida, o Tu a borboleta. Porém, não como se fossem sempre estados que se alternam nitidamente, mas, amiúde, são processos que se entrelaçam confusamente numa profunda dualidade. (1)

A alteridade se instaura somente na relação Eu-Tu, no relacionamento Eu-Isso o outro não é encontrado como Outro em sua alteridade, ou seja, o Outro não pode ser apreendido na plenitude da sua diferença. (2)

Em reposta a relação Eu-Tu, surge a responsabilidade. A resposta é dada seja na omissão, seja na ação, sendo fundamental na relação e ocorre no entre da relação. ${ }^{(4)}$

O Entre é o espaço que se abre na relação do Eu com o Tu, onde o inter-humano se relaciona. No domínio do inter-humano cada um é para o outro um parceiro num acontecimento da vida. O entre é aquilo que está genuinamente na relação. Ele não tem caráter e continuidade, mas é sempre de novo reconstruído em cada encontro. É nesse entre Outubro, 2016:2(Edição Especial):86-103. 
do relacionamento que se torna possível a aceitação e confirmação dos dois polos envolvidos no evento da alteridade. Buber refere que é no entre dos relacionamentos que o ser se manifesta e conhece o mundo. (1)

(...) que cada um dos dois se torne consciente do outro de tal forma que precisamente por isso assuma para com ele um comportamento, que não o considere e não o trate como seu objeto mas como seu parceiro num acontecimento da vida, mesmo que seja apenas uma luta de boxe. (1)

Para que o encontro se estabeleça Buber define uma condição básica para a sua realização que ele denomina de pré-consciência, assim sendo, o conhecimento de si próprio se faz essencial para a realização do encontro e da ética. A ética definirá os limites do Ser.(2)

Para Buber 'entre' é a expressão mais adequada para a ética. Desse encontro nasce a responsabilidade uma vez que a abertura me coloca em contato com o Outro, o diferente, 'o que não está em mim'. A responsabilidade para com o Outro é, portanto para Buber, a resposta ao apelo dialógico. Trata-se de uma responsabilização mútua uma vez que na relação ambos são ao mesmo tempo Eu-Tu, desse modo de um lado o Eu é o fundamento da relação e da ética da responsabilidade, do outro lado da conversa o Tu sendo Eu complementa este fundamento existencial. A responsabilidade transcende o nível moral, para um nível mais amplo: a ética da reciprocidade. ${ }^{(6)}$

Nas atitudes humanas pautadas pelas relações éticas e responsáveis o Eu reconhece que a sua realidade essencial é a de se relacionar com o outro $(\mathrm{Tu})$, reconhecendo-o em sua alteridade. Para que a ética do inter-humano, do encontro e da responsabilidade aconteça se faz necessário conhecer o outro, relacionar-se com ele. Sendo assim a ética torna-se o eixo dos relacionamentos, onde a palavra princípio Eu-Tu é proferida de igual maneira. Este é o princípio de uma ética estabelecida na reciprocidade, onde o Eu se dirige ao Tu na forma de uma dupla ação mútua, de uma resposta autêntica que se realiza nos encontros da existência comum. ${ }^{(3)}$

A verdadeira responsabilidade se encontra onde há resposta. A responsabilidade se torna o nome ético da reciprocidade. ${ }^{(4)}$

O que acontece no Entre das relações não deve ser entendido em forma de sentimentos. O que ocorre é a ação essencial e recíproca, imediata que une dois seres e acontece entre os dois. Os sentimentos são possuídos pelo Eu, eles acompanham as relações tal como o amor acompanha os sentimentos. ${ }^{(1)}$

A relação se estabelece no encontro face a face, na presença do outro, na sua totalidade e unicidade de abertura ao encontro. Na presença do outro. ${ }^{(1)}$

Outubro, 2016:2(Edição Especial):86-103. 
Buber propõe ao homem a realização de uma vida dialógica e não pautada no monólogo. O dialógico seria o desdobramento da esfera do entre que acontece quando duas pessoas se abrem uma a outra para um encontro genuíno e sem resistências. O elemento fundamental para que o diálogo aconteça é a reciprocidade. ${ }^{(3)}$

O movimento contrário, o monológico é o 'dobrar-se-em-si-mesmo', é negar a essência do seu ser. O Outro aqui se torna apenas uma parte do meu Eu. A vida monológica é aquela que se nega a se relacionar. O homem monológico não está consciente da alteridade do outro, pois tenta incorporar o outro a si mesmo. ${ }^{(3)}$

Buber aponta que o pressuposto para uma relação genuína acontecer é ver o outro como ele é tomando como conhecimento que esse é essencialmente outro. Trazendo novamente a noção de alteridade, essencial nas relações. ${ }^{(2)}$

O motivo que levaBuber a escrever esta filosofia do encontro seria o de despertar a nostalgia do humano. Ele reconhece cada indivíduo como sendo apto a se tornar uma pessoa única, singular e portadora de uma tarefa do ser que somente ela pode cumprir.(6)

O homem é antropologicamente existente não no seu isolamento, mas na integridade da relação entre homem e homem: é somente a reciprocidade da ação que possibilita a compreensão adequada da natureza humana. ${ }^{(1)}$

O fato existencial é um ser humano existindo ao lado de outro ser humano, cuja individualidade só pode ser entendida na relação com o outro. (1)

\section{ALTERIDADE E RECIPROCIDADE: uma visão buberiana}

Os conceitos de alteridade e reciprocidade são constantes no que se refere às relações e têm sido discutidos com relativa frequência por várias ciências, dentre elas a psicologia. $A$ temática ajuda a compreender de que forma o Eu pode se dirigir ao Outro e se relacionar com ele de forma genuína. ${ }^{(7)}$

Alteridade é diferença e, nas relações, diz-se que é a capacidade de colocar-se no lugar do Outro, ser capaz de apreender o Outro na plenitude da sua dignidade, dos seus direitos e, sobretudo, da sua diferença. ${ }^{(8)}$

O termo alteridade aparece como a dimensão de outro, ou mais adequadamente falando da relação com um outro. O encontro com um outro, portanto entendido enquanto alteridade, é característico de toda e qualquer atividade humana.

Outubro, 2016:2(Edição Especial):86-103. 
[...] o plano das relações, onde se dá o inelutável encontro dos seres, encontro no qual cada um afeta e é afetado,o que tem por efeito uma instabilização da forma que constitui cada um destes seres, produzindo transformações irreversíveis. Em outras palavras, a existência inelutável do plano da alteridade define a natureza do ser como heterogenética. ${ }^{(9)}$

Buber refere-se que tanto a constituição da subjetividade quanto a descoberta da alteridade, são fenômenos ligados à relação, pois para que o homem encontre a si mesmo, é preciso que ele encontre o seu companheiro, conhecendo-o em toda a sua alteridade como ele mesmo e se decida a partir em direção a ele, rompendo sua solidão e fazendo acontecer um encontro transformador. ${ }^{(5)}$

Vygotsky permite ainda afirmar que, mais do que reconhecer o pouco que é seu descobrindo o muito que não teve e o que não terá, o encontro permanente e incessante com um outro possibilita reconhecer a pluralidade do que se é e do que se pode vir a ser. ${ }^{(7)}$

O outro que nos cerca é diferente de nós, o que torna a alteridade essencial na relação, onde esse diferente será compreendido e respeitado como tal. (4)

A reciprocidade por sua vez é descrita como a capacidade intelectual através da qual se torna compreensível a relação entre dois ou mais elementos do mundo comum, mutuamente percebidos no espaço, de aspecto e forma integrantes. Em sua ética deve-se agir em favor do outro como se nos dirigíssemos a nós mesmos. Reciprocidade significa dar e receber;representa mutualidade. ${ }^{(2)}$

O começo é a relação, e a relação é reciprocidade:(1)

Relação é reciprocidade. Meu Tu atua sobre mim assim como eu atuo sobre ele. Nossos alunos nos formam, nossas obras nos edificam. $\mathrm{O}$ "mau" se torna revelador no momento em que a palavra-princípio sagrada o atinge. Quanto aprendemos com as crianças e com os animais! Nós vivemos no fluxo torrencial da reciprocidade universal, irremediavelmente encerrados nela. ${ }^{(1)}$

A vivência humana na totalidade implica a ação recíproca que, longe de menosprezar a singularidade do homem, por sua vez, valoriza-a. A totalidade do ser humano abarca o fato de que o homem é o ser a ser compreendido, mas ao mesmo tempo, denota o próprio ser que compreende, que conhece o sentido de sua existência. ${ }^{(3)}$

$\mathrm{O}$ auge dos relacionamentos proporciona o desabrochar entre sujeitos, fomentando o aparecimento do cuidado que se dá como meio para o crescimento do homem como pessoa, possibilitando o apoio ao outro que se encaminha para a sua auto realização. Tal ação recíproca encerra não somente a afirmação de alteridade do outro, mas também a 
confirmação desse outro. É neste instante da relação, da afirmação do outro como pessoa, que a verdadeira humanidade é possível. ${ }^{(10)}$

Martin Buber sonhava com uma comunidade de alteridade e reciprocidade. Este parte do princípio que:"o homem só pode conhecer sua essência em e na relação com o outro. Dirigindo-se a este de em sua alteridade e fundamentado nos princípios da reciprocidade".(1)

No entanto, apesar de sua enorme fé no humano, em 1923, Buber já vislumbrava uma tendência da contemporaneidade de indivíduos doentes, entendida por ele por uma degradação do sentido humano. ${ }^{(1)}$

Tal crise na humanidade se estabelece segundo Buber, em consequência de se olhar o TU como ISSO: "E com toda seriedade da verdade, ouça: o homem não pode viver sem o Isso, mas aquele que vive somente com o Isso não é homem." (1)

$\mathrm{Na}$ contemporaneidade o sujeito sofre com o reflexo de ter sido considerado apenas como um ser histórico-social, determinado pela cultura de seu tempo. (23)

As reflexões de Buber datam do início do século passado, mas ainda hoje permanecem extremamente importantes e pertinentes, pois a era tecnológica e seus avanços, a sociedade atual com suas eternas exigências de consumo e capacitação, continuam impelindo o homem a uma perda de sentido, a uma valorização do mundo do Isso, em detrimento ao mundo das relações autênticas, ou mundo do Tu. ${ }^{(11)}$

\section{EU-OUTRO: O outro da relação}

Considerando que o humano se constitui nas relações que estabelece com o mundo, compreender a inter-relação entre o "Outro" e "Eu" torna-se fundamental para diversas áreas do saber. Na tradição das reflexões e debates - sejam eles filosóficos, científicos, psicológicos, antropológicos, artísticos enfim... as mais diversas áreas, o tema 'Outro' tem sido amplamente abordado, inspirando algumas elucubrações sobre a temática que são pertinentes para este trabalho, pois fazem parte do cenário teórico de Martin Buber inserido de maneira fundamental. ${ }^{(5)}$

Jacques-Marie Émile Lacan, psicanalista francês refere que a palavra seja a mediação do eu com o outro, e que é da sua essência agarrar-se ao outro. O nível no qual o outro é vivido situa exatamente em que nível o eu existe para o sujeito. O eu é referente ao outro, ele se constitui em relação ao outro, é seu correlato. Apontando assim a importância do outro para o eu. Lacan faz referências a dois outros, sendo o Grande outro (A), e o outro (a)..$^{(12)}$

Grande outro $(\mathbb{A})$ tem o propósito de diferenciar esse Outro (a), como lugar da palavra, simbólico, único movimento teórico através das quais a palavra constitui o sujeito que nos Outubro, 2016:2(Edição Especial):86-103. 
determina dos "outros" (com 'a' minúsculo) que são as pessoas com as quais nos relacionamos, nos identificamos e às vezes nos confundimos. Para Lacan era necessário fazer essa distinção, dentre outras razões, porque o Outro como lugar da palavra possui uma autonomia que faz com que ele não possa ser reduzido ao que os pequenos outros enunciam. Essa dependência da linguagem na determinação do sujeito é certamente uma das grandes marcas da teoria lacaniana. ${ }^{(12)}$

Sobre o Outro relata: "O outro que não é outro coisa nenhuma, já que ele é essencialmente acoplado com o eu, numa relação sempre reflexiva, intercambiável - o ego é sempre um alter-ego." (12)

O sujeito é um elo do discurso do Outro, onde muitos estão encadeados: "uma família inteira, um bando inteiro, uma facção inteira, uma nação inteira ou a metade do globo". Assim para Lacan a realidade do inconsciente origina-se a partir de um complexo de muitos sujeitos. ${ }^{(12)}$

O sujeito se vê a partir do outro em outro lugar. É por isso que ele tem um eu imaginário, construído à imagem e semelhança do outro. Na medida em que o sujeito os põe em relação com sua própria imagem, aqueles com quem fala, são também aqueles com quem se identifica. Ao falar do Outro, Lacan parece dar conta da relação do homem com tudo aquilo que determina boa parte do seu modo de ser. ${ }^{(12)}$

Outro discípulo de Freud que fez considerações importantes sobre o Outro, Carl Gustav Jung, fundador da psicologia analítica, traz a noção de eu queprojeta no outro aquilo que não consegue resolver consigo mesmo, dessa forma relata: Tudoo quenosirrita nos outros pode nos levar àuma compreensão sobre nós mesmos. ${ }^{(13)}$

Ignorando assim as próprias fraquezas e projetando no outro aquilo que é percebido como falha nos outros, mascara o sentimento do eu em relação a ele mesmo. É projetado no outro por não ser aceito pelo Eu. ${ }^{(13)}$

Acredita ainda que o encontro de duas personalidades se assemelha ao contato de duas substâncias químicas: se alguma ação ocorre, ambos sofrem uma transformação. ${ }^{13)}$

Afastando-se na linha de leitura psicanalítica - apesar de sustentar certa inspiração nela - Jean-Paul Charles Aymard Sartre, filósofo francês, conhecido como representante do existencialismo, acredita ser através do olhar que o eu reconhece o outro e se relaciona com ele. O olhar torna-se o ponto imprescindível para a condição humana no estabelecimento da relação Eu-Outro. ${ }^{(14)}$

Para Sartre é no encontro entre os seres que ocorre a identidade e o sentido do Ser; esta seria a relação original estabelecida pelo ato do olhar. Esse olhar implica em um reconhecimento do outro e, por meio disso, um reconhecimento de si, do eu. Tal relação está assim posta uma vez que para Sartre o ponto central da existência é o agir no mundo, um agir Outubro, 2016:2(Edição Especial):86-103. 
sempre contemplado pela liberdade e, mesmo assim, comprometido com um senso de responsabilidade para com o próprio eu e para com o mundo. Para Sartre, a liberdade e a responsabilidade pela ação só podem acontecer num contexto relacional ou à luz da existência do Outro - pois se fundamenta no reconhecimento do Outro.(15)

Sartre em sua célebre frase 'O inferno são os outros', traz uma perspectiva da relação onde o outro é irremediavelmente meu inferno, pois diante dele, ao mesmo tempo que sou compelido a agir, sou cerceado em minha liberdade de ação. Para o autor, o encontro de duas liberdades resultará numa tentativa mútua de imposição, ou, dito de outra maneira, num encontro há conflito de liberdades onde uma tenta submeter a outra a si. A contradição existe uma vez que a reflexão também revela que o eu é afirmado e reconhecido pela consciência do outro, diante da pluralidade desse outro, ou seja, é assim que ele efetivamente passa a existir. ${ }^{(15)}$

A presença do outro seria como uma extensão do eu, que estariam intimamente ligados e revelados ao olhar do outro. Essa revelação do eu ao outro provocaria um incômodo que Sartre nomeia de mal estar, pois o outro é revelado ao eu. ${ }^{(16)}$

É impossível segundo Sartre, negar a realidade do encontro, não há como fugir de conhecer a si mesmo e de conhecer o outro, mesmo que o eu negue a si mesmo e ao outro, não há como retroceder, pois um está refletido no outro. Essa é a facticidade do ser-paraoutro. (15)

Como um artifício utilizado pelo indivíduo, este pode ter uma conduta pautada no que Sartre relata ser a 'máscara da má-fé', ou apenas 'má-fé' onde acontece uma negação do eu e do outro diante de serem revelados, pois não querem que sua intimidade seja invadida, e para isso dissimulam suas intenções de acordo com a análise que o outro faz de si. ${ }^{(16)}$

Esses meios utilizados para dissimilar as intenções do ser diante do outro, destroem a sua consciência. É, portanto, uma autodestruição da consciência. Ainda assim sob esta nova face do ser, o eu e o outro não conseguem manipular as emoções vivenciadas no primeiro encontro. ${ }^{(15)}$

Emmanuel Lévinastem sua obra pautada na ética da responsabilidade em relação ao outro, sendo reconhecido enquanto um filósofo da ética da alteridade, e por isso conhecido como o Filósofo da Alteridade. Valoriza então a realidade que emerge da relação do Eu com o Outro, estando o humano imerso em uma realidade relacional. ${ }^{(8)}$

Sendo a auto realização do homem uma forma original da dialética do mesmoe do outro, ela não é senão a efetivação existencial do paradoxo segundo o qual o homem se torna ele mesmo, na sua abertura constitutiva ao outro, abertura esta atravessada pelo apelo profundo a uma generosidade do dom de si mesmo, que podemos

Outubro, 2016:2(Edição Especial):86-103. 
denominar como razão metafísica, na medida em que ela é, em nós, o signo de que não podemos realizar-nos a nós mesmos senão como seres abertos à infinitude do Ser.(17)

O Outro, na alteridade, é um rosto que se apresenta diante do $\mathrm{Eu}$, em uma relação face a face, e que exige do Eu um comportamento ético que o permita ser, isto é, existir de forma diferente. Todo o pensamento filosófico de Lévinas tem como base a relação com o outro e sua experiência plural. Ele propõe que o eu se abra em sua alteridade para o outro, e em especial ao que o outro me traz de diferente, de desigual exatamente como se encontra, sem indiferença ou exclusão por suas particularidades. Refere que a relação com o outro é face a face, desprovida de toda mediação. O face-a-face é o ético por excelência e como o originalmente humano. ${ }^{(8)}$

Segundo Lévinas é a partir da ética que o Ser encontra seu verdadeiro sentido, que é a sua relação com outro, sendo esta pautada na responsabilidade, de modo a não reduzir o outro a si mesmo. ${ }^{(8)}$

\section{INFLUÊNCIA DE BUBER NA PSICOTERAPIA}

Uma característica marcante na psicologia como área do conhecimento é o fato dela ter diferentes referências teórico-metodológicas que pautam a atuação do psicólogo. Abordagens nas mais diversas modalidades, incluindo terapia cognitivo-comportamental, rogeriana, gestaltista, sistêmica, grupal, comportamental, psicanálise, humanista e fenomenológica existencial, são algumas dentre várias existentes e seus possíveis desdobramentos. Não há uma única e unificada perspectiva. Tal e qual a psicoterapia fenomenológica-existencial, como uma abordagem dentro da psicologia possui inúmeras ramificações que se evidenciam através da influência de diferentes pensadores, filósofos e psicólogos. ${ }^{(3)}$

Apesar da variedade de compreensões e conceituações do que seja a psicoterapia, podemos nos apoiar em alguns autores e em suas definições a respeito. A psicoterapia é entendidacomo um procedimento técnico de um vínculo humano, baseado num referencial teórico da estrutura da personalidade e dos comportamentos das relações interpessoais, mediante o qual se estabelece um vínculo de ajuda para algum tipo de assistência, visando aliviar ou melhorar suas condições atuais de vida, e assim, atingir um melhor nível de desenvolvimento enquanto ser humano. ${ }^{(18)}$

Outubro, 2016:2(Edição Especial):86-103. 
A psicoterapia de abordagem existencial é entendida como sendo decorrente, fundamentalmente, de uma corrente filosófica, pautada na reflexão e questionamento da existência humana. Tradicionalmente atribui-se a Soren Kierkegaard o início da reflexão sobre a existência como tema para a filosofia e saber. Desde então um dos pontos predominantes dos pensadores existencialistas é a própria existência pessoal como ponto fundamental na análise de pressupostos existências que possam determinar contrapontos da sua própria existência. Existência, na origem é sinônimo de mostrar-se, exibir-se, movimento para fora. ${ }^{(18)}$

Assim o existencialismo seria uma maneira de o homem expor a si mesmo, reconhecendo-o nesse ato, fazendo-o de forma consciente. Portanto o existencialismo seria a expressão de uma experiência singular, onde se reconhece que o indivíduo é único e irrepetível, não podendo ser comparado, nem tão pouco determinado.(18)

O fundamento do psicoterapeuta seria, portanto, criar uma relação de confiança, promovendo um espaço seguro e adequado para se realizar uma investigação, uma exploração da maneira como a pessoa está no mundo. Clarificar e descrever, em primeiro lugar, o modo como a pessoa é em e na relação. ${ }^{(19)}$

A relação terapêutica, sem caminhos previamente estabelecidos, constitui-se assim como espaço de construção entre sujeitos que se colocam numa posição propícia para perspectivar o horizonte de possibilidades que se abrem. Assim sendo há uma forte contribuição para a prática clínica de abordagem fenomenológica-existencial, advinda de Martin Buber. ${ }^{(10)}$

Seu legado é amplamente utilizado como material teórico que pauta a prática de vários profissionais que entendem que através de seus escritos seja possível fazer e experienciar uma psicoterapia legítima, sem barreiras, e que coloque os sujeitos num processo autêntico e de mutualidade. ${ }^{(2)}$

Dentre suas principais ideias estão as palavras-princípio, Eu-Tu e Eu-lsso que demonstram as duas dimensões da filosofia do diálogo queabarcam a existência. ${ }^{(1)}$

A partir desse pensamento abre-se a possibilidade de se refletir sobre a importância do encontro tanto em um âmbito pessoal, quanto como reflexão teórica para a atuação do profissional psicólogo. Este questiona o conhecimento humano afirmando-o falho quando considerou o homem através do individualismo bem como do coletivismo, uma vez que o homem só pode ser entendido na relação com o outro. ${ }^{(10)}$

Cada homem tem o dever de saber... que jamais houve no mundo ninguém igual a ele, pois caso houvesse existido alguém igual a ele não haveria necessidade de que nascesse. Cada homem é um ser novo no mundo, chamado a realizar sua particularidade no mundo. ${ }^{(1)}$

Outubro, 2016:2(Edição Especial):86-103. 
Sua filosofia pautada na humanidade, afirma que o humano não é um objeto de análises exatas, mas sim uma construção da própria situação humana da reflexão, utilizando dessa forma também a fenomenologia de Husserl para pensar no indivíduo e suas manifestações. (3)

Quanto à relação psicoterápica, ela deve ser uma busca permanente do modo de ser Eu-Tu que inclui a afirmação do outro como pessoa, o reconhecimento que terapeuta e cliente são o mesmo tipo de ser, além de uma postura propícia à abstenção de julgamento para que o paciente possa ser encontrado sem obstáculos, na sua singularidade. (1)

O psicoterapeuta em seu trabalho com os clientes, 'é essencialmente um ser humano...'; consequentemente, explora e ama o ser humano que são os pacientes, aceitandoo conforme se apresenta, fazendo-o presente para si, sempre de novo. ${ }^{(19)}$

Sem dúvida na relação terapêutica o conhecimento científico não só é necessário como também indispensável, mas sua presença no projeto terapêutico não deve impor-se em detrimento da própria experiência de dualidade de pessoas que se relacionam mutuamente no diálogo.

O encontro na terapia não acontece entre um cientista e seu objeto de investigação, mas ao contrário, acontece entre duas pessoas mediadas pela relação de ajuda. A presença do terapeuta torna-se a primeira e talvez a sua principal intervenção ao longo de todo o processo terapêutico. ${ }^{(20)}$

Esta orientação terapêutica de abertura dialógica com o paciente se assenta nas orientações defendidas por Buber. Este partepois do pressuposto de que: a mente jamais adoece sozinha senão que sempre está subjacente a um problema de relacionamento: de entreidade, uma situação de falta de uma relação dialógica entre ela e outro ser existente. (21)

É na prioridade do diálogo que o sentido mais profundo da existência humana é revelado. É nessa possibilidade dialógica que faz do contexto terapêutico tão valioso, pois neste paciente e terapeuta se encontram e se relacionam nas suas alteridades e reciprocidades, reverberando a mutualidade do encontro. (21)

Bons e maus, inteligentes e tolos, bonitos e feios, uns e outros serão verdadeiramente um para o outro, um tu [...] único e existente frente ao outro [...] e assim pode ele atuar, ajudar, curar, educar, enaltecer, libertar. ${ }^{(1)}$

Buber influenciou com sua filosofia, diferentes escolas psicoterápicas e modelos médicos, como Laura e Fritz Perls e Victor Frankl, bem como J.L.Moreno, Hans Trub, entreidade Yung, e ainda reverbera sua doutrina na corrente filosófica do existencialismo e na psicoterapia dialógica. ${ }^{(22)}$

Outubro, 2016:2(Edição Especial):86-103. 
No entanto, é sempre importante lembrar que, apesar desta influência Buber não se considera um doutrinário, chegando a dizer que não teria nenhum ensinamento a transmitir, além de um diálogo. "Tomo aquele que me ouve pela mão e levo até a janela. Abro-a e aponto para fora. Não tenho ensinamento algum, mas conduzo um diálogo." (1) Paradoxalmente, é inegável que adotando esta postura, ele nos legou muitos ensinamentos, que servem de alicerce para se pensar uma prática de atenção e cuidado, a nomeada: psicoterapia dialógica.

\section{A POSTURA DIALÓGICA NO ENCONTRO TERAPEUTA-CLIENTE}

A psicoterapia dialógica ressalta a potencialidade da relação humana na sua concretude e movimento. Seria esta uma terapia centrada no encontro do terapeuta com seu cliente com o objetivo central de cura, independentes de quais técnicas terapêuticas estejam sendo utilizadas. É uma forma de abordagem e não pertence a nenhuma escola específica. (21)

O dialógico acontece no entre um espaço das ocorrências humanas, não se trata de um constructo lógico, mas inato ao ser humano, ao entrar em relação Eu-Tu. Segundo Friedmam (2002), a vida dialógica é uma obrigação do ser humano e somente através dela pode-se alcançar uma vida autêntica. A esfera do "entre" é o espaço, onde o encontro dialógico acontece. Este constitui um espaço de trocas e não pertence a nenhum dos participantes, uma vez que pertence a ambos e os ultrapassa. ${ }^{(10)}$

O primeiro movimento que se dá nesse contexto de terapia dialógica, seria segundo Buber a inclusão. A inclusão no sentido do terapeuta abarcar, compreender a experiência do cliente tal qual este a verbaliza. ${ }^{(10)}$

A inclusão postula que ao encontrar-se com o outro e sua história pode-se imaginar realmente aquilo que se escuta, possibilitando sentir o que o cliente sente, mas sem perder a própria identidade, é estar em sintonia com o outro, porém sem deixar de ser quem é. (21)

Para que isso ocorra, devem-se ser aliados a certos comportamentos a esta prática inclusiva: $1^{a}$ ) o de fazer presente para o cliente "o que está pensando, sentindo e experienciando", sem renunciar a sua função de terapeuta de não transgredir os limites normativos de uma mutualidade curativa; $2^{\mathrm{a}}$ ) o de "aceitar, afirmar e confirmar" o cliente no seu modo de ser singular atual e projetado; no entanto, a confirmação não se trata de simplesmente concordar com a experiência que é relatada pelo outro; vai infinitamente além, visto que, pode-se confirmar uma pessoa, mesmo não estando de acordo com suas atitudes; $3^{a}$ ) o de dar ênfase ao ato de 'confirmar', pois: a base da vida interpessoal é o desejo que Outubro, 2016:2(Edição Especial):86-103. 
cada pessoa tem de ser confirmada (aceita, apoiada) tal como ela é e tal como possa vir-aser. (21)

Seriam ainda necessários para o processo de cura a 'a atualização e liberação' das forças internas bloqueadas do psiquismo do consulente, e, dessa forma, sentir-se livre para alcançar a plena realização de sua singularidade e autenticidade. $O$ único caminho para desimpedir este potencial é o do exercício da vida dialógica, que a terapia restaura. ${ }^{(10)} \mathrm{Ou}$ seja, o problema da cura existencial não residiria em restaurar a integridade perdida do indivíduo (seu sintoma), senão em ativar as potencialidades psíquicas para realização da sua singularidade ou de tornar-se pessoa (seu enigma).

A eficiência desse modelo psicoterápico se assenta nestas premissas inseparáveis: a da etiologia relacional das afecções propriamente psíquicas; a da força indestrutível da mente humana para restabelecer, superando os obstáculos, a sua vida dialógica, como condição para sua saúde e realização da sua singularidade. ${ }^{(21)}$

Segundo Carl Rogers, em seu clássico diálogo com Martin Buber, datado de 1957, nos momentos de encontro genuíno desaparecem as diferenças de posição e intenção entre terapeuta e cliente e este encontro torna-se então fecundo em reciprocidade e passível de crescimento e transformação para ambos. Rogers reconhece a convergência de pensamentos com Buber, que norteiam ambos modelos psicoterápicos e aspectos técnicos que orientam a prática terápica, principalmente na postura dialógica do terapeuta, que possibilitam liberar forças psíquicas estagnadas no consulente, permitindo a realização da própria singularidade. Para ambos é importante o processo de tornar-se pessoa, ou seja a realização da própria singularidade, e ainda os de preservar os limites de uma mutualidade curativa, que implica certo distanciamento e ausência de envolvimento emocional. ${ }^{(10)}$

A postura dialógica significa mais especificamente o vínculo terapêutico, também descrito como aliança terapêutica, o fator que influencia diretamente no curso do tratamento, na adesão ao processo e na avaliação de resultados. ${ }^{(19)}$

Tal postura dialógica permite colocar-se na relação como pessoa real, todavia sustentada por um aparato teórico. Isto é, torna-se possível ao psicólogo uma atitude de 'amor terapêutico', sem, contudo, confundir-se, pois é uma relação especificamente profissional. Outro aspecto importante a ser observado é a possibilidade que a atitude dialógica abre também para o crescimento do terapeuta, visto que este, ao aceitar olhar para o outro despojado de seus preconceitos, dispõe-se a ser tocado por cada cliente e apreender uma riqueza que se encontra na história de vida de cada ser, que é único e dotado de possibilidades. $^{(11)}$

Outubro, 2016:2(Edição Especial):86-103. 
Esta perspectiva humana da psicoterapia dialógica amplia as possibilidades de um atendimento para além da técnica e do psicologismo, ampliando assim os horizontes de atuação do profissional psicólogo. ${ }^{(20)}$

\section{CONCLUSÃO}

Partindo da problemática do encontro, contemplada especialmente nas elucubrações de Buber, pode-se refletir brevemente sobre temas fundamentais para a prática terapêutica e que tocaram particularmente esta estudante de psicologia durante o início de seu processo contínuo- de formação. Problematizar o lugar do outro na relação fez que emergissem a fundamental importância desse outro para a formação identitária desse Eu, que se evidenciou conforme a convergência de vários estudiosos citados neste trabalho.

O legado de Martin Buber torna-se, portanto, um referencial atual e prático, sobre as relações; relações essas entre um Eu e um Outro, que são imprescindíveis para o Eu. A utilização prática de sua teoria abrange o âmbito pessoal, bem como o profissional e torna a prática psicoterápica um local de encontro genuíno em sua alteridade.

O contexto atual bem como o contexto psicoterápico depara-se com esse indivíduo, em extremo sofrimento, que encontra dificuldades para se relacionar com o outro, que não consegue estabelecer um encontro ou diálogo entre sujeitos, tão essenciais para a existência de ambos. Tal fato tem favorecido um adoecimento em larga escala do indivíduo que cada vez mais busca na psicoterapia soluções para seu sofrimento, estabelecendo assim um processo psicoterápico de mutualidade, legítimo e autêntico, reverberando o encontro na clínica para a vida dos indivíduos, tal que ele se reproduza em outros contextos.

Sendo assim, o processo psicoterapêutico, pautado nos legados de Martin Buber, com o estabelecimento de uma postura dialógica, além da utilização de outras técnicas aliadas a psicoterapia existencial, já se inicia como um processo de cura, apenas pelo fato de terapeuta e paciente ocuparem posições horizontais de diálogo, estando livres de qualquer processo que ao invés de aproximar paciente-terapeuta os afaste. Através desse encontro singular, para ambos, o processo é experienciado, onde o principal fator para a efetividade é a qualidade da relação entre terapeuta e consulente. Existir vai além de ser quem se é; se faz necessário ser com o outro. A essência do indivíduo se revela no encontro com o outro.

Outubro, 2016:2(Edição Especial):86-103. 


\section{REFERÊNCIAS}

1. Buber M. Eu e Tu. Tradução, introdução e notas por: Newton Aquiles Von Zuben. São Paulo: Centauro. 2001.

2. Souza V. A Religião do encontro: a ética de Martin Buber. [Internet]. Revista Theos. 2016 [cited 28 April 2016]. Available from:

http://www.revistatheos.com.br/Artigos/05 Vitor.pdf

3. Gomes Pedro B. A filosofia do relacionamento. Revela. Periódico de Divulgação Científica da Fals. [Internet]. São Paulo; s.d. [2016 mar. 20].

http://www.fals.com.br/revela18/REVELA\%20XVII/artigo\%204_VI.pdf

4. Carrara O. Vicente. A Relação em Martin Buber. s.t [Internet]. Bauru; s.d. [2015 abr. 28]. http://www.usc.br/biblioteca/mimesis/mimesis_v23_n1_2002_art_06.pdf

5. Vonzuben N. Martin Buber: Cumplicidade e Diálogo. 2nd ed. Bauru: EDUSC; 2003.

6. Mendes Zuleide P. Martin Buber e a relação eu/tu: Inversão e recíproca de inversão nas relações. Instituto Packter [Internet]. São Paulo; s.d.. [2015 abr. 28]. http://institutointersecao.com.br/artigos/Zuleide/MONOGRAFIA BUBER-Zuleide.pdf

7. Zanella Andréa $V$. Sujeito e alteridade: reflexões a partir da psicologia históricocultural.. Psicologia \& Sociedade [Internet]. Santa Catarina; s.d. [2016 jan. 10]. http://www.scielo.br/pdf/psoc/v17n2/27049.pdf

8. Costa M. Lévinas: uma introdução. Petrópolis: Vozes; 2000.

9. Rolnik S. Diálogo e alteridade. Boletim de Novidades. 1992.

10. Ramom S. A psicoterapia dialógica de Martin Buber. Goiânia: Psico; 2010.

11. Ferreira Viviane G. S, Parreira Gisele G. A relação dialógica e o processo de cura em psicoterapia. Pontifícia Universidade Católica de Goiás - PUC - GO [Internet]. Goiânia; s.d. [2016 jan. 10]. http://itgt.com.br/wpcontent/uploads/2013/06/TCC_Viviane-Guimarães-da-Silva-Ferreira.pdf

12. Brauer Jussara F. O outro em Lacan: consequências clínicas. Instituto de Psicologia USP [Internet]. São Paulo; s.d. [2016 mar. 18]. http://pepsic.bvsalud.org/pdf/psicousp/v5n1-2/a20v5n12.pdf

13. Vergueiro Paola V. Jung entrelinhas: reflexões sobre os fundamentos da teoria Yunguiana. Psicologia, Teoria e Prática [Internet]. 2008 [2016 mar. 15];1(10):125143. http://pepsic.bvsalud.org/scielo.php?script=sci_arttext\&pid=S151636872008000100010.

14. Sartre J. P. O existencialismo é um humanismo. São Paulo: Nova Cultura; 1987.

15. Gonçalves Aline I. O problema do outro em Sartre [dissertação]. Santa Maria, RS: Universidade Federal de Santa Maria (UFSM, RS);2012. 
16. Jacoby Márcia, Carlos Sérgio A. O eu e o outro em Jean Paul Sartre: pressupostos de uma antropologia filosófica na construção do ser social. Latin-American Journal of Fundamental Psychopathology on Line [Internet]. São Paulo; s.d. [2015 jun. 01] http://www.fundamentalpsychopathology.org/uploads/files/latin_american/v2_n2/o_ eu_e_o_outro_em_jean_paul_sartre.pdf

17. Vaz H. Antropologia Filosófica. São Paulo: Loyola; 2004.

18. Camom V. Psicoterapia existencial. São Paulo: Pioneira; 1993.

19. Jardim Adriano Souza, Mariane Gomes, Willian. O self dialógico e a psicoterapia: uma compreensão dialógica da relação terapeuta-paciente. Periódicos Eletrônicos em Psicologia [Internet]. São Leopoldo; s. d. [2016 abr. 02].

http://pepsic.bvsalud.org/scielo.php?script=sci_arttext\&pid=S198334822009000100001

20. Luczinsky Giovana F. Ancona-Lopez, Marília. A psicologia fenomenológica e a filosofia de Buber: o encontro na clínica. Estudos de Psicologia [Internet]. Campinas; s.d. [2016 abr. 02].

http://www.scielo.br/scielo.php?script=sci_arttext\&pid=S0103-166X2010000100009

21. Hyckner R. De pessoa a pessoa: uma psicoterapia dialógica. São Paulo: Summus, 1995.

22. Marcolino J. A., lacoponi E. Escala de Aliança Psicoterápica da Califórnia na versão do paciente.Rev. Bras. Psiquiatr. [online]. 2001, vol.23, n.2, pp.88-95. ISSN 15164446. http://dx.doi.org/10.1590/S1516-44462001000200007.

23. Carrijo Ferreira, L.; Souza Camargo Próchno, C.; Castilho Romera, M. O Encantamento como Possibilidade de Conhecimento e as Vicissitudes do real. Psicologia e Saúde em Debate, v. 1, n. 2, p. 55-70, 2015. 